\section{Pruning Time $\times$ Cultivar Effects on Flower-bud Hardiness in Northern Highbush and Southern Highbush Blueberry}

\author{
Mark K. Ehlenfeldt ${ }^{1}$ \\ United States Department of Agriculture, Agricultural Research Service, P.E. \\ Marucci Center for Blueberry and Cranberry Research and Extension, \\ Chatsworth, NJ 08019
}

\author{
Bryan T. Vinyard \\ United States Department of Agriculture, Agricultural Research Service, \\ Henry A. Wallace Beltsville Agricultural Research Center, Biometrical \\ Consulting Service, Beltsville, MD 20705
}

Additional index words. Legacy, Jersey, $\mathrm{LT}_{50}$, Vaccinium darrowii, Vaccinium corymbosum

Abstract. A study was conducted to determine if early-fall pruning (vs. more typical winter pruning) of either northern highbush or southern highbush blueberries was detrimental to the development of optimum levels of mid-winter cold hardiness in floral buds under New Jersey conditions. Using a detached-shoot freeze-thaw assay, flower-bud $\mathbf{L T}_{50}$ values were determined in early January for both 'Jersey' (northern highbush) and 'Legacy' (southern highbush) blueberry bushes that had been subjected to early- or latepruning protocols. Across 2 years, intrinsic differences due to genotype and genotype $\times$ year were present, but no significant differences due to pruning time were observed. The lack of pruning effects on flower-bud $\mathbf{L T}_{50}$ values suggests that cultivars with southern germplasm selected in areas such as North Carolina and further north may be treated similarly to northern highbush with respect to pruning time, including early-fall pruning.

As blueberry cultivar development advances, increasing numbers of new cultivars released for north-temperate areas contain some amount of southern-adapted germplasm, usually Vaccinium darrowii Camp (typically <12\%) (Brevis et al., 2008; Ehlenfeldt, 1994; Hancock and Siefker, 1982). $V$. darrowii is cold sensitive, has virtually no chilling requirement, and grows natively only in Florida and southern areas of adjoining states (Vander Kloet, 1988). V. ashei Reade (rabbiteye blueberry) and $V$. tenellum Aiton may also be present at low levels (usually $1 \%$ to $2 \%$ or less). Cultivars being grown or tested in more northern areas that have $V$. darrowii in their background include 'Draper' (Hancock, 2004), 'Legacy' (USDA-ARS, 1993), 'Sweetheart' (USDA-ARS, 2010), 'Ozarkblue' (Clark et al., 1996), and 'Cara's Choice' (Ehlenfeldt et al., 2005). Some of these cultivars, especially 'Legacy', retain their leaves considerably longer in the fall than typical northern highbush (pure $V$. corymbosum L. cultivars). 'Legacy' (a southern highbush cultivar with $25 \%$ V. darrowii) often retains its leaves until early January, when leaves may freeze off,

\footnotetext{
Received for publication 22 Dec. 2014. Accepted for publication 19 Mar. 2015.

This research was partially supported though a gift from the New Jersey Blueberry and Cranberry Research Council.

${ }^{1}$ To whom reprint requests should be addressed; e-mail mark.ehlenfeldt@ars.usda.gov.
}

rather than senesce. Measurements of acclimation and deacclimation in 'Legacy' have shown that it does not reach as deep of a level of dormancy/cold hardiness as northern highbush cultivars and normally begins deacclimating by early January (Ehlenfeldt et al., 2012; Rowland et al., 2005).

Empirical observations by growers and researchers have suggested that late-season fertilization and/or early-fall pruning of traditional northern highbush are undesirable because they may stimulate growth and delay dormancy (Highbush Blueberry Production Guide, 1992). 'Brigitta Blue' particularly is noted as a cultivar that is slow to go dormant and one that should not be late-fertilized because of risk of winter damage (Penn State Cooperative Extension, 2013). Beyond these empirical observations, however, almost no experimental documentation exists of such effects in blueberry. In crops such as apple, survey-based studies have documented the detrimental effects of practices that delay vegetative maturation (Anthony et al., 1936). Similarly, late-fall pruning of apples has been documented as resulting in greater cold damage than winter pruning (Burkholder, 1936).

Currently, commercial growers in New Jersey prune blueberry bushes at variable times, often dependent on when labor is available. Pruning can begin as early as late September before plants have gone fully dormant, and when temperatures still average about $16{ }^{\circ} \mathrm{C}$. It can only be assumed that, in general, these growers consider the detrimental effects to be minor.

In the face of the lack of published information on cold hardiness of blueberries with respect to pruning times, we conducted this study in the interest of establishing "good practice" information for the growing of newer southern-germplasm introgressed cultivars in northern locations. This study subjected 'Legacy', a southern highbush cultivar with relatively high levels of $V$. darrowii (25\%), and 'Jersey' (0\% V. darrowii) to early- and late-pruning regimes, and determined the effects on cold hardiness and flower-bud survival. This information is important to developing management practices for new and future cultivars such as these and the others described.

\section{Materials and Methods}

Determination of flower-bud cold hardiness. For freeze assays, 5- to 6-cm-long shoots with three to eight flower buds were subjected to a freeze-thaw protocol as described previously (Arora et al., 1997). The protocol consisted of placing three randomly sampled shoots per treatment temperature from each genotype in test tubes (three shoots/tube) with $0.5 \mathrm{~mL}$ of water and subjecting them to controlled freezing in a glycol bath (Model FP 45; Julabo USA Inc., Allentown, PA). Samples were allowed to equilibrate for $\approx 45 \mathrm{~min}$ at $-1{ }^{\circ} \mathrm{C}$ and then further cooled at $0.5{ }^{\circ} \mathrm{C} / 30 \mathrm{~min}$ down to $-4{ }^{\circ} \mathrm{C}$, at $1{ }^{\circ} \mathrm{C} / 30$ min down to $-8{ }^{\circ} \mathrm{C}$ and at $2{ }^{\circ} \mathrm{C} / 30$ min intervals thereafter to respective final treatment temperatures. A range of five treatment temperatures were selected covering a range from -18 to $-30{ }^{\circ} \mathrm{C}$ at $3{ }^{\circ} \mathrm{C}$ increments to cover a $0 \%$ to $100 \%$ injury range of blueberry flower buds for these genotypes at this point in the acclimation cycle (Arora et al., 1997). Shoots were removed from the freezer bath at respective treatment temperatures $\left(-18,-21,-24,-27\right.$, and $\left.-30{ }^{\circ} \mathrm{C}\right)$, thawed overnight at $4{ }^{\circ} \mathrm{C}$, and incubated at $20{ }^{\circ} \mathrm{C}$ for $24 \mathrm{~h}$. Subsequently, the three most distal buds were dissected and observed for injury (visual browning of the inflorescence primordia in individual flower buds) (Arora et al., 2000; Flinn and Ashworth, 1994). Each bud was rated for the number of injured and noninjured ovaries and a percent injury was determined for each bud. In total, data from 90 dissected buds were collected for use in each $\mathrm{LT}_{50}$ determination for subsequent statistical analyses. Controls were similarly handled shoots that were kept at $4{ }^{\circ} \mathrm{C}$ with no exposure to the glycol freezing bath.

Experimental design. This experiment was carried out at the P.E. Marucci Center for Blueberry and Cranberry Research and Extension (Rutgers University), Chatsworth, $\mathrm{NJ}$ in a plot containing several highbush cultivars, including 'Jersey' (northern highbush) and 'Legacy' (southern highbush). Within the block, each cultivar was planted in three replicates of 20 plants each. All bushes in the block were planted in 2005 
and were considered to be mature plants. Within each replicate of 20 plants, 10 plants were selected that were most uniform in size, number of fruiting canes, and so forth, and half of these (five plants) were designated for early-pruning (late September/early October), the other half for late-pruning (early March).

Weather data from both years were accessed from a networked statewide weather substation located at the Rutgers University facility (New Jersey Weather \& Climate Network, 2014). Archived data provided records of daily means, as well as daily highs and lows that were used to calculate weekly means as appropriate.

Pruning and sampling in Year 1. For 2012-13, early-pruned plants were pruned on 1 Oct. 2012. The plants were pruned assertively, with the goal of eliciting an effect. To do this, three to four mature canes were removed from each bush, with the goal of removing about $35 \%$ to $40 \%$ of the total number of canes. In most cases this was accomplished by the removal of three canes. Plants pruned on this day were flagged for later identification. Plants representing a latepruning practice were not pruned until 15 Mar. 2013 (i.e., after cold hardiness evaluations were made); however, sampling protocols were standardized so that shoots were only sampled from canes that would normally remain after pruning (i.e., younger, vigorous, and well-structured canes).

On 2 Jan. 2013, six cuttings (terminal shoots) were taken from each of five earlypruned plants in each of the three replicates, and an equal number were taken from latepruned plants in the same replicates, with special efforts made to take comparable shoots (i.e., location and development) from each plant. These shoots were subjected to a freezer bath chilling-protocol to determine the $\mathrm{LT}_{50}$ (temperature at which $50 \%$ of the inflorescence primordial are killed) for each cultivar $\times$ pruning treatment $\times$ replicate. This entire process was replicated on 7 Jan. 2013.

Pruning and sampling in Year 2. In 201314, plants were pruned on 27 Sept. 2013. The plants were pruned more aggressively in Year 2 , removing $45 \%$ to $50 \%$ of the canes. An effort was also made to select plants that appeared to have recently active shoots. In all but one or two cases, the plants selected for pruning were not the same plants that had undergone early pruning the year before. Plants were flagged for later identification. Late-pruned plants were not pruned until 14 Mar. 2014 (after cold hardiness determinations were made). Shoots were sampled from early- and late-pruned plants for a first replicate on 8 Jan. 2014, and on 13 Jan. 2014 for a second replicate, and samples were treated and evaluated as in 2012-13.

Statistical analysis of bud cold-hardiness data. Bud cold hardiness was defined as the temperature causing $50 \%$ lethality among inflorescence primordia $\left(\mathrm{LT}_{50}\right)$. To calculate the $\mathrm{LT}_{50}$, nine data points (three shoots $\times$ three proximal buds) for each genotype/ temperature were resampled $(n=9$ with replacement) 30 times (Manly, 1997). A sigmoidal regression was made of percent injury vs. temperature for each of the 30 sets of resampled data, and the 30 resulting values of $\mathrm{LT}_{50}$ (and their lower and upper confidence limits) were averaged to obtain bootstrap $\mathrm{LT}_{50}$ estimates for each evaluation date. The $\mathrm{LT}_{50}$ estimates were compared among genotypes and treatments by analysis of covariance (Milliken and Johnson, 2002).

Using this process, thirty bootstrap $\mathrm{LT}_{50}$ estimates were obtained and averaged for each Date/Rep and Year for both of the genotypes and both of the pruning times (Rowland et al., 2005). A Genotype $\times$ Pruning $\times$ Year ANOVA and means comparison was conducted, allowing for heterogeneous within Genotype $\times$ Pruning variance, as determined by likelihood ratio test via the COVEST homogeneity statement, and using the residual group option in the RANDOM statement of SAS PROC GLIMMIX (SAS Institute Inc., 2010).

\section{Results and Discussion}

Weather conditions. In Year 1, for the week of early-pruning, the average weekly minimums, maximums, and daily means were $13.8,23.7$, and $18.6{ }^{\circ} \mathrm{C}$, respectively (56.9, 74.6, and $\left.65.4{ }^{\circ} \mathrm{F}\right)$. Overall, Year 1 (2012) was the milder of the 2 years (Fig. 1). In Year 1, the lowest single-day temperatures leading up to the two evaluation dates was $-6.1{ }^{\circ} \mathrm{C}$, which occurred on three dates: 24 Dec., 2 Jan., and 3 Jan. (Weeks 11 and 12). The mean of daily-low-temperatures for the week before evaluation (23 Dec. to $29 \mathrm{Dec}$., Week 12) was $-2.1{ }^{\circ} \mathrm{C}$. Coldest single-day temperatures of winter were between 23 Jan. and 27 Jan. (Weeks 15 and 16, postevaluation) with 4 days having lows of -14.4 to $-15{ }^{\circ} \mathrm{C}$.

In Year 2, for the week of early-pruning, the average weekly minimums, maximums, and daily means were $8.8,25.2$, and $16.4{ }^{\circ} \mathrm{C}$, respectively $\left(47.8,77.4\right.$, and $\left.61.6^{\circ} \mathrm{F}\right)$. Overall, Year 2 (2013) had several cooler weeks before the evaluation dates than did Year 1 (Fig. 1). In Year 2, the lowest temperatures leading up to the evaluation dates were $-12.8{ }^{\circ} \mathrm{C}$ ( $3 \mathrm{Jan}$.), $-19.4{ }^{\circ} \mathrm{C}$ (4 Jan.), $-16.1{ }^{\circ} \mathrm{C}$ (7 Jan.), and $-15.6^{\circ} \mathrm{C}(8 \mathrm{Jan}$.) (Weeks 13 and 14). The mean of daily-low-temperatures the week before evaluation was $-7.6{ }^{\circ} \mathrm{C}$ ( 29 Dec. to 4 Jan., Week 14). Some of the coldest single-day temperatures of winter occurred between 21 Jan. and 31 Jan. with 8 days of temperatures in the range of -12.7 to $-22.8^{\circ} \mathrm{C}$ (Weeks 17 and 18 , postevaluation). The single date with the coldest low was $-22.8^{\circ} \mathrm{C}$ on 30 January (Week 18, postevaluation).

Cold hardiness. We evaluated $\mathrm{LT}_{50}$ as early as feasible in January; this was a time that previous studies indicated was optimal, since a wide range of genotypes had been observed previously to reach their maximal cold hardiness by this point (Ehlenfeldt et al., 2012). In these earlier studies, southern highbush were observed to begin deacclimating after this point, whereas northern highbush typically retained their cold acclimation for about another 7 weeks.

Analysis of treatments from Year 1 suggested that differences between pruning practices, as we measured them for this study, were minor or nonexistent (Table 1). Since negligible effects were seen in Year 1, the next set of plants was pruned more aggressively in Year 2, with cane removal averaging $45 \%-50 \%$ (compared with $35 \%-40 \%$ in Year 1). Efforts were also made to select

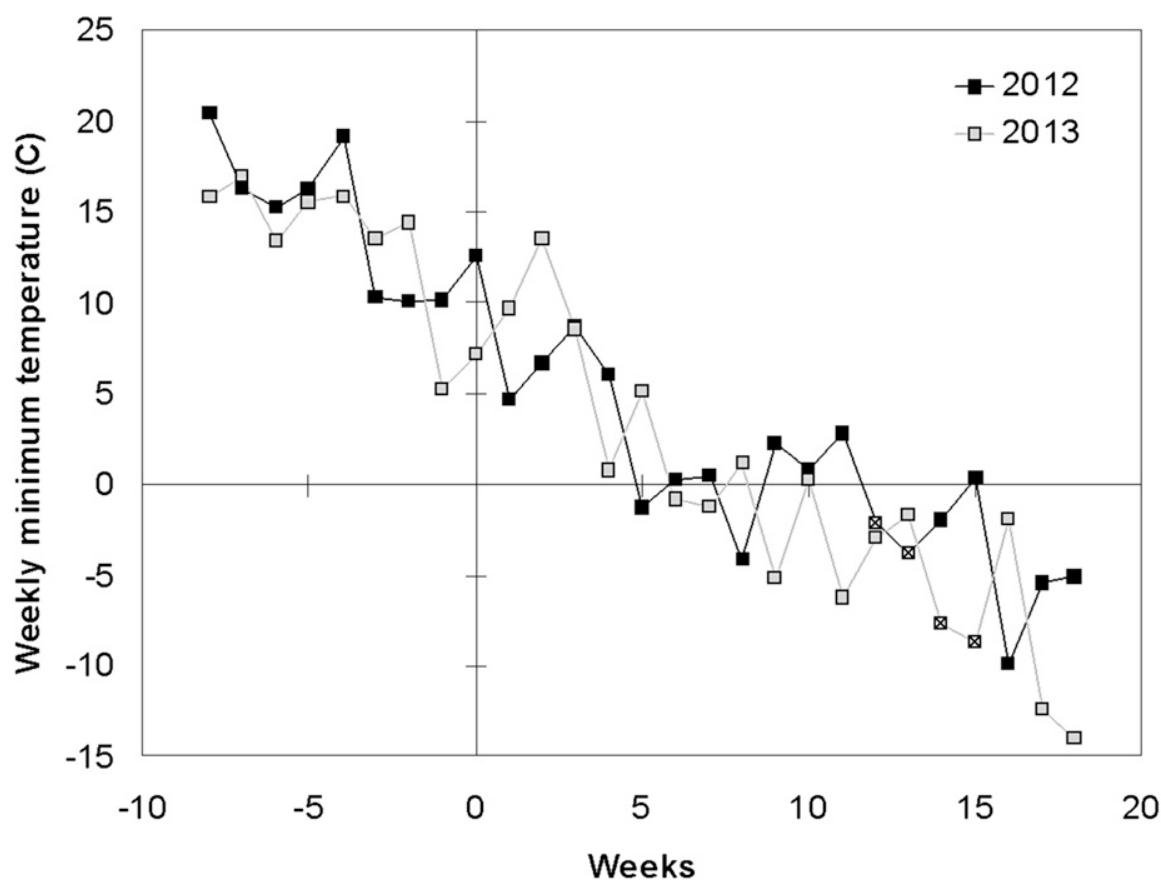

Fig. 1. Weekly averages of daily minimum temperatures in 2012-13 and 2013-14. Week 0 is the week of pruning (late September/early October). Data points with crosses denote the weeks of evaluations (early to mid-January). 
Table $1 . \mathrm{LT}_{50}$ values (temperatures causing 50\% flower-bud primordia lethality) for 'Jersey' and 'Legacy' blueberry buds across 2 years (2012-13), with two pruning dates.

\begin{tabular}{lcccr}
\hline & & \multicolumn{3}{c}{$\mathrm{LT}_{50}\left({ }^{\circ} \mathrm{C}\right)^{\mathrm{z}}$} \\
\cline { 3 - 5 } Cultivar & $\mathrm{Yr}$ & Early-pruned & Late-pruned & $\mathrm{LT}_{50} \Delta^{\mathrm{y}}$ \\
\hline Jersey (northern highbush) & 2012 & $-29.0 \mathrm{c}$ & $-28.8 \mathrm{c}$ & 0.2 \\
& 2013 & $-29.1 \mathrm{c}$ & $-28.4 \mathrm{c}$ & 0.7 \\
Legacy (southern highbush) & 2012 & $-20.7 \mathrm{a}$ & $-21.7 \mathrm{a}$ & -1.0 \\
& 2013 & $-23.4 \mathrm{~b}$ & $-24.0 \mathrm{~b}$ & -0.6 \\
\hline
\end{tabular}

${ }^{\mathrm{z}} \mathrm{A}$ single analysis analyzed cultivars, treatments, and years. Values with different letters across either rows or columns are significantly different at a $P=0.05 P$ level.

${ }^{\mathrm{y}} \mathrm{LT}_{50}$ early $-\mathrm{LT}_{50}$ late difference. A negative value for $\Delta$, if significant would indicate that the early-pruned plants were less hardy.

plants that appeared to have recently active shoots.

Cold hardiness, when analyzed across 2 years showed no significant differences for early-pruning vs. late-pruning for either cultivar $(F=0.34, P=0.5767)$ (Table 1$)$.

There were, however, significant differences observed between cultivars for innate cold hardiness, with 'Legacy' being typically 5 to $7{ }^{\circ} \mathrm{C}$ less hardy than 'Jersey' depending upon the specific year and treatment $(F=$ $347.18, P<0.001)$. This difference between 'Legacy' and 'Jersey' is similar to that observed in earlier studies that evaluated 'Legacy' vs. 'Bluecrop' (northern highbush), which found $\mathrm{LT}_{50}$ values of -24.1 and $-26.9{ }^{\circ} \mathrm{C}$ for 'Legacy' and 'Bluecrop', respectively (Ehlenfeldt et al., 2012). 'Legacy' also exhibited significant within genotype response between the 2 years, with 2012 exhibiting warmer $\mathrm{LT}_{50}$ values than 2013 (Table 1). These responses are in accord with 2013 being a colder year than 2012 .

In both years, 'Legacy' had negative $\Delta \mathrm{LT}_{50}$ values $\left(\mathrm{LT}_{50 \text { early }}-\mathrm{LT}_{50 \text { late }}\right)$, whereas the values for 'Jersey' were positive. Surprisingly, the more aggressive pruning and colder temperatures that occurred in Year 2 did not result in a larger $\Delta \mathrm{LT}_{50}$ value being observed in 'Legacy'.

These results are valuable because they provide experimental evidence on two important issues: (1) fall pruning is not detrimental to typical northern highbush, thus supporting some grower practices, but also contrary to some dogma, and (2) fall pruning is not detrimental to southern highbush that have been developed under more northerly conditions such as 'Legacy', which often appear to take much longer to achieve the outward appearance of dormancy. It suggests that in cases of well-adapted cultivars with small percentages of southern ancestry, fall pruning is not detrimental to flower-bud survival. 'Legacy', with $25 \% \mathrm{~V}$. darrowii ancestry, has more southern-adapted ancestry than the other cultivars listed that are being tested under northern conditions, and thus might be expected to be a cultivar far more likely to exhibit damage. Since it did not, other cultivars with lesser amounts are likely to perform similarly or better; however, further cultivars should be tested before definitive conclusions are reached. As noted earlier, most southern highbush cultivars begin to slowly deacclimate beginning in late December, thus the greatest threat to such selections with southern germplasm in most years appears not to be mid-winter cold hardiness, so much as susceptibility to late winter/early spring cold spells. Such susceptibility would be expected to be largely independent of pruning regimes. Southern highbush cultivars typically also bloom earlier than northern highbush; hence damage may occur to these tissues in southern highbush at a time when northern highbush still retain a certain tolerance to cold temperatures.

The question may be asked as to whether the early pruning regime significantly affected the hardiness of vegetative tissue. We did not specifically examine this. The cold winter of 2013 resulted in tip dieback on numerous cultivars. Observations of the plants during the summer seasons however suggested no differential effects on plant growth for either of the two summers following pruning treatments.

\section{Literature Cited}

Anthony, R.D., R.H. Sudds, and W.S. Clarke, Jr. 1936. Low temperature injury to orchards in Pennsylvania and adjoining states in the fall and winter of 1935-36. Proc. Amer. Soc. Hort. Sci. 33:33-43.

Arora, R., L.J. Rowland, and G.R. Panta. 1997. Chill responsive dehydrins in blueberry: Are they associated with cold hardiness or dormancy transitions? Physiol. Plant. 101:8-16.

Arora, R., L.J. Rowland, J.S. Lehman, C.C. Lim, G. R. Panta, and N. Vorsa. 2000. Genetic analysis of freezing tolerance in blueberry (Vaccinium section Cyanococcus). Theor. Appl. Genet. 100:690-696.

Brevis, P.A., N.V. Bassil, J.R. Ballington, and J.F. Hancock. 2008. Impact of wide hybridization on highbush blueberry breeding. J. Amer. Soc. Hort. Sci. 133:427-437.

Burkholder, C.L. 1936. December pruning in 1935 results in severe injury to Jonathan and Stayman trees at Lafayette, Indiana. Proc. Amer. Soc. Hort. Sci. 33:49-51.

Clark, J.R., J.N. Moore, and A.D. Draper. 1996. 'Ozarkblue' southern highbush blueberry. HortScience 31:1043-1045.

Ehlenfeldt, M.K. 1994. The genetic composition and tetrasomic inbreeding coefficients of highbush blueberry cultivars. HortScience 29:1342-1345.

Ehlenfeldt, M.K., L.J. Rowland, E.L. Ogden, and B. Vinyard. 2012. Cold-hardiness, acclimation, and deacclimation among diverse blueberry genotypes. J. Amer. Soc. Hort. Sci. 137:31-37.

Ehlenfeldt, M.K., A.W. Stretch, N. Vorsa, and A.D. Draper. 2005. 'Cara's Choice' blueberry. HortScience 40:1556-1557.

Flinn, C.L. and E.N. Ashworth. 1994. Blueberry flower-bud hardiness is not estimated by differential thermal analysis. J. Amer. Soc. Hort. Sci. 119:295-298.

Hancock, J.F. 2004. Blueberry plant denominated 'Draper'. U.S. Plant Patent 15,103 P2 filed 23 Jan. 2003 and issued 24 Aug. 2004.

Hancock, J.F. and J.H. Siefker. 1982. Levels of inbreeding in highbush blueberry cultivars. HortScience 17:363-366.

Highbush Blueberry Production Guide (NRAES55). 1992. Northeast regional agricultural and engineering service, p. 200. Ithaca, NY.

Manly, B.F.J. 1997. Randomization, bootstrap and Monte Carlo methods in biology. 2nd Ed. Chapman \& Hall, London, UK.

Milliken, G.A. and D.E. Johnson. 2002. Analysis of messy data - volume III: Analysis of covariance. Chapman \& Hall/CRC, London, UK.

New Jersey Weather \& Climate Network. 9 Aug. 2014. <www.njweather.org/station/317>

Penn State Cooperative Extension. 2013. The midAtlantic Berry guide, p. 273. Penn State University, University Park, PA.

Rowland, L.J., E.L. Ogden, M.K. Ehlenfeldt, and B. Vinyard. 2005. Cold hardiness, deacclimation kinetics, and bud development among 12 diverse blueberry (Vaccinium spp.) genotypes under field conditions. J. Amer. Soc. Hort. Sci. 130:508-514

SAS Institute Inc. 2010. SAS/STAT ${ }^{\circledR} 9.22$ user’s guide, p. 8444. SAS Institute Inc., Cary, NC.

USDA-ARS. 2010. Notice of release of sweetheart highbush blueberry. USDA-ARS, Washington, D.C.

USDA-ARS and New Jersey Agricultural Experiment Station - Rutgers University. 1993. Notice of release of Legacy highbush blueberry. Washington, D.C.

Vander Kloet, S.P. 1988. The genus Vaccinium in North America. Publ. 1828. Agr. Can. Res. Branch, Ottawa, Ontario, Canada. 